\title{
A New Window on the Universe
}

In April 1933, at a small gathering at a meeting of the US National Committee of the International Scientific Radio Union (URSI), Bell Labs scientist Karl Guthe Jansky announced that he had detected 20.5 MHz (14.6 m) radio emission from the Milky Way. Jansky used a novel directional antenna based on an invention by AT\&T Bell Labs colleague, Edmond Bruce, that rotated every 20 minutes to determine the direction and source of the interfering noise that was plaguing the telephone company. Jansky's remarkable discovery of what he called "star noise" was widely publicized in the media, but had little immediate impact in the astronomical community, as astronomers, who typically had little background in electronics or radio, saw no relation to their own work.

For more than a decade, the only significant progress was made by one individual, Grote Reber, who had just graduated from college with a degree in electrical engineering. His 32 foot parabolic dish, which he built in the yard next to his mother's house using his own funds, was the forerunner of the much larger radio telescopes later built in the UK, in Australia, and later the United States, as well as the millions of smaller dishes which have proliferated throughout the world for the reception of satellite-based TV broadcasting. With his home-built radio telescope, Reber detected galactic radio noise first at $160 \mathrm{MHz}(1.9 \mathrm{~m})$ then $480 \mathrm{MHz}(62 \mathrm{~cm})$, which he called "cosmic static." Reber recognized the nonthermal nature of the galactic radio emission, made the first radio maps of the Milky Way, discovered the intense radio emission from the Sun, and brought radio astronomy to the attention of the astronomical community.

\subsection{Star Noise at the Telephone Company ${ }^{1}$}

The first transatlantic telephone circuits were established by AT\&T in 1927 between New York and London using very long wavelength $5 \mathrm{~km}(60 \mathrm{kHz})$ radio transmissions (Bown 1927). The following year, the AT\&T Bell System 
inaugurated a short wavelength circuit to provide a greater capacity. Although the Bell System transatlantic telephone calls were very expensive, they were subject to interference and fading and were not very reliable. Little was known at the time about short wave radio propagation or the limits to weak signal reception. Some noise originated in the receiver systems, but some was external. Some of the external static clearly came from passing automobiles and airplanes or from local thunderstorms, but some came from an unknown origin (Oswald 1930). According to Al Beck (1984), members of the Bell Labs radio research staff were aware that when connected to an antenna, the receiver noise was greater than when connected to a load, and that the level of noise depended on the antenna and the time of the day. So, it was understood that at least some of the noise was apparently external to the receiver system.

Still only 22 years old, on 20 July 1928, Karl Jansky reported for his first day of work at the AT\&T Bell Telephone Laboratories, joining the tightly knit members of the Radio Research Division (Fig. 1.1). By August, after a twoweek orientation class, Jansky was working at the Cliffwood Laboratory in New Jersey, little realizing that he was about to embark on an engineering

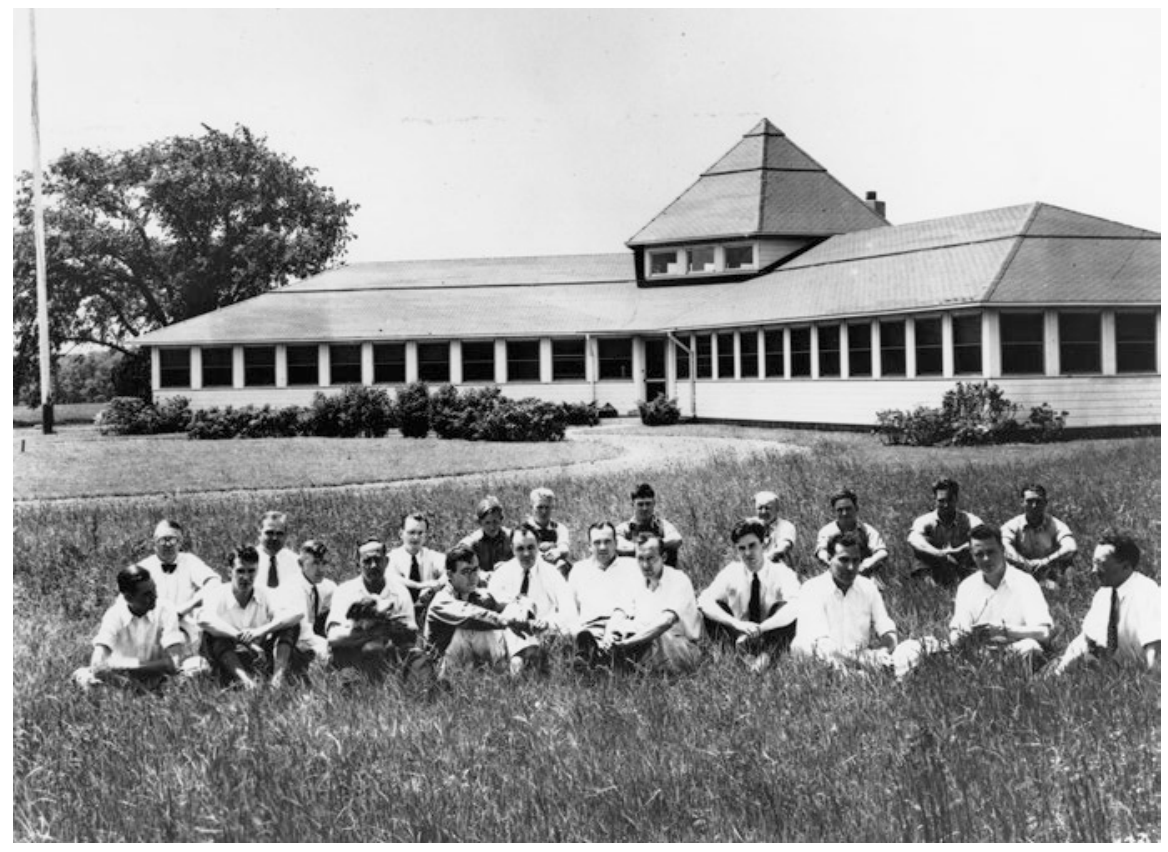

Fig. 1.1 Members of the Bell Labs Radio Research Division. Shown in the first row from left to right: Art Crawford, Carl Feldman, Sam Reed, Joe Johlfs, Lewis Lowery, Russell Ohl, Bill Mumford, Karl Jansky, Merlin Sharpless, Archie King, Edmund Bruce, and $\mathrm{Al}$ Beck. In the second row are Carl Englund, Harald Friis, Douglas Ring, Otto Larsen, Carl Clauson, Morris Morrell, Carl Peterson, Maurice Collins, Dan Schenk, and Jim Morrell. Credit: Courtesy of J.A. Tyson 
study leading to a series of discoveries that would fundamentally change our understanding of the Universe and its constituents. Radio galaxies, quasars, pulsars, the Cosmic Microwave Background (CMB), cosmic evolution, cosmic masers, gravitational lensing, electrical storms on Jupiter, and other now commonly known cosmic phenomena were all unknown until Karl Jansky opened the new radio window to the Universe.

Karl Guthe Janksy was born on 22 October 1905 in the territory of Oklahoma, where his father Cyril was Dean of the University of Oklahoma College of Engineering. Karl was named after Karl Guthe who was a former professor of his father at the University of Michigan. Karl grew up in Madison, Wisconsin, where his father became a Professor of Electrical Engineering at the University of Wisconsin.

Karl's older brother, Cyril Moreau Jansky, Jr., known as C.M. Jansky, Jr., and to his family and to his friends as "Moreau," received a BA in Physics in 1917 and MS in 1919, both from the University of Wisconsin. Following his graduation, he taught at the University of Minnesota, where one of his first students was Lloyd Berkner, who would go on to become the driving force behind the formation of the National Radio Astronomy Observatory as the first President of Associated Universities (Sect. 3.1). C.M. Jansky, Jr. worked briefly for Bell Labs, and played a leading role in the development of radio technology and regulation in the US. In 1930, with his former student, Stuart Bailey, he established the consulting firm of Jansky and Bailey, where he remained active until his death in 1975. In 1934, Jansky became President of the Institute of Radio Engineers (IRE), the predecessor to the current Institute of Electrical and Electronic Engineers (IEEE).

Like his brother, Karl also studied physics at the University of Wisconsin and received his BS in Physics in 1927, graduating Phi Beta Kappa with a thesis titled, "Conditions for Oscillations in a Vacuum Tube Circuit." While at Wisconsin, Karl was the fastest skater and a prolific scorer on the university ice hockey team, and later while working at Bell Labs, he was the table tennis champion of Monmouth County, New Jersey. After a year in graduate school, ${ }^{2}$ Karl sought a job at Bell Labs. Although Bell Labs was initially unenthusiastic about hiring Karl, who had a chronic kidney disease, Moreau intervened on behalf of his brother and urged the Bell Labs president to hire Karl (Jansky 1957). ${ }^{3}$ In recognition of his illness, instead of locating him at their main laboratory in industrial New York City, Karl was sent to their then small rural laboratory in Cliffwood Beach, New Jersey, where he began work to study the propagation of short wave radio transmissions and the noise limits to transatlantic telephone communications. He married Alice Larue Knapp the following year, and along with most of the other Bell Labs Cliffwood employees, Karl and his growing family lived in nearby Red Bank. Karl enjoyed the informal social life shared with his fellow engineers. In spite of his illness and against medical advice, he remained active. He played chess, tennis, and golf, enjoyed bowling and skiing, had the highest batting average on the softball team, and was a passionate bridge player who claimed to know what cards each of the 
players held. Karl was an avid Brooklyn Dodgers baseball fan and had very strong political opinions. He was critical of the Roosevelt administration and speculated that if the president's term was ten years instead of four that, "We might have another civil war."

Throughout his career at Bell Labs, Karl's immediate boss was Harald Friis, a Danish-American radio engineer who had immigrated to the United States from Denmark and had established a reputation in radio antennas and propagation. Later Friis and his wife Inge became close personal friends of the Jansky family, and were godparents to Jansky's daughter Anne Moreau. With time, tensions developed between Jansky and Friis over Karl's work assignments, but apparently their personal relationship remained intact.

Jansky's discovery of cosmic radio emission is a classic example of the scientific method, complete with false leads, that George Southworth (1956) later compared to a Sherlock Holmes detective story. Jansky's story is described in his series of papers in the Proceedings of the IRE (Jansky 1932, 1933b, 1935), his laboratory notebook entries, ${ }^{5}$ and regular weekly work reports, as well as the running account of his work documented in his detailed letters to his father back in Madison. ${ }^{6}$ These letters provide a glimpse into the development of Karl's thinking as he acquired and interpreted new data, and reflected on the difficult economic challenges he and his young family faced during those trying depression years.

In order to determine the direction of interfering signals, Jansky needed a directional antenna whose orientation could be varied. His notebook entries for 22 to 29 June 1929 indicate that he devoted this period to the design of a rotating antenna. On 24 August, he noted, "Mr. Sykes was interviewed and will start work on the 'merrygoround' next Monday." The next months were spent designing and building the instrumentation with special attention to reducing receiver noise and obtaining good gain stability (Beck 1984). During this period, Jansky also planned the rotating Bruce Array ${ }^{7}$ at Cliffwood Beach which was constructed by Carl Clausen, a member of the Bell Labs staff. Jansky's rotating array used a parasitic reflector to enhance the forward gain and directivity, and was mounted on the wheels and axles taken from an old Ford Model T car. ${ }^{8}$ Motor driven, the array made a complete rotation in azimuth every 20 minutes. Jansky's work was interrupted by a decision to move the Laboratory to a new location at Holmdel, New Jersey, which would provide more room for the growing laboratory staff and less noise and local interference. A new circular track was constructed away from the laboratory building, and the rotating Bruce array was relocated to the new site (Fig. 1.2).

One of Karl's first tasks at the new site was to find a frequency free of interfering signals. On 10 May 1930, he wrote, "It was decided to operate upon a frequency of $20,689.7$ [kc] or 14.5 meters." $\mathrm{He}$ then calculated the size of the quarter wave antenna elements as " 142.72 inches $=11$ feet 10.72 inches or 11 $\mathrm{ft}$ 103/4 approx." A week later, on 17 May he wrote, "I designed the supporting framework for the array proper. The diagrams have been turned over to the shop office." 


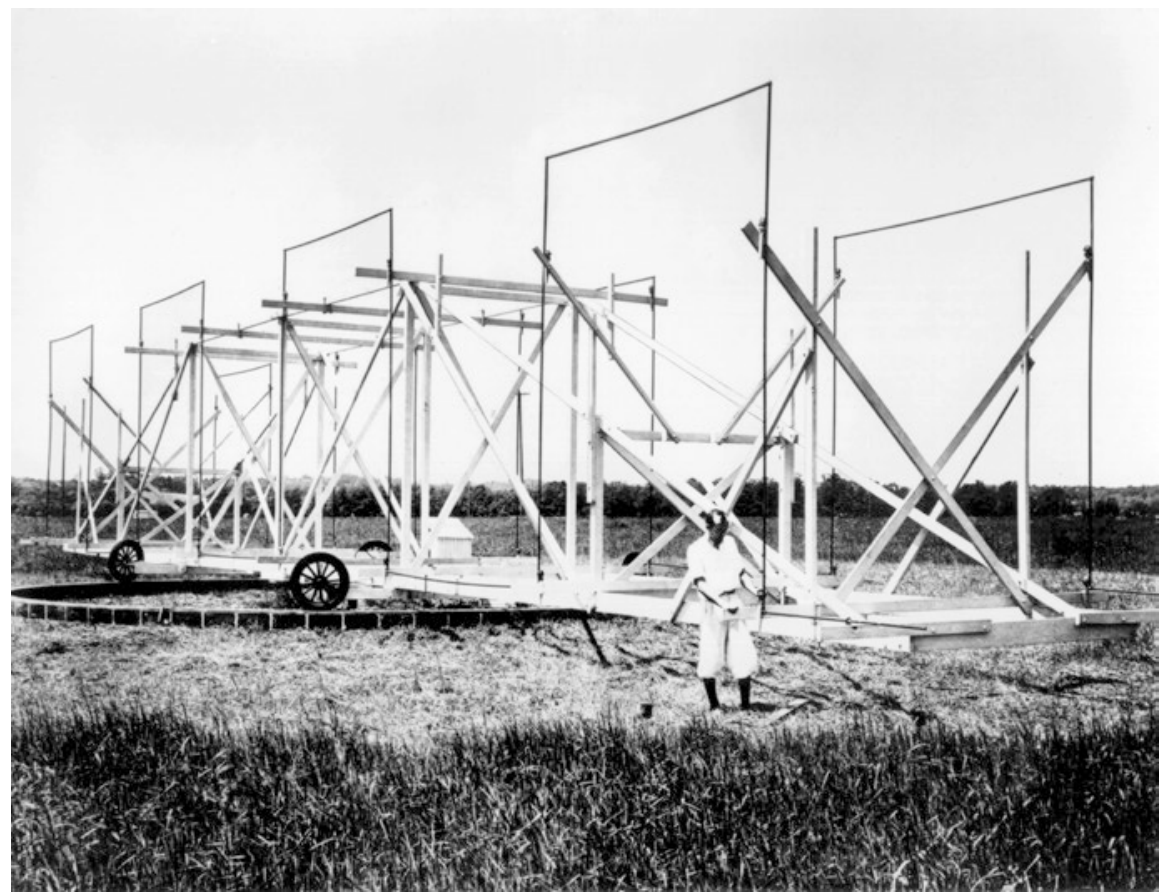

Fig. 1.2 Karl Jansky and his rotating Bruce Array known as the "merry-go-round," which he used in 1932 to detect radio emission from the Milky Way Galaxy. Credit: NRAO/AUI/NSF

During the summer and autumn of 1930, Karl used his rotating array to determine the direction of arrival of signals from transmitting stations in England and South America and easily detected static from nearby thunderstorms. ${ }^{10}$ In November he became aware of static coming from a direction where there was no obvious weather disturbance, but apparently much of Jansky's time during his period was spent on other activities (Southworth 1956). Following an overhaul of his receiving system, he began in the summer of 1931 to keep more systematic records of displayed static on a running paper chart recorder (Fig. 1.3). During the 1931/1932 winter, after the summer thunderstorm activity had subsided, he noted that the anomalous noise was highly peaked in a direction that appeared to move with the time of the day, being strongest in the morning toward the east, toward the south at noon, and toward the west late in the afternoon. Jansky naturally concluded that it had something to do with the Sun, and wrote to his parents, "That would be interesting wouldn't it?"11 Coincidently, in December the Sun lies in the direction of the Milky Way, and over the following months the peak noise came earlier each day, and Jansky noted that it was well removed from the Sun. However, he apparently did not yet realize that the source was extraterrestrial. 
Fig. 1.3 Karl Jansky examining the output of his paper chart recorder. Credit: NRAO/AUI/ NSF

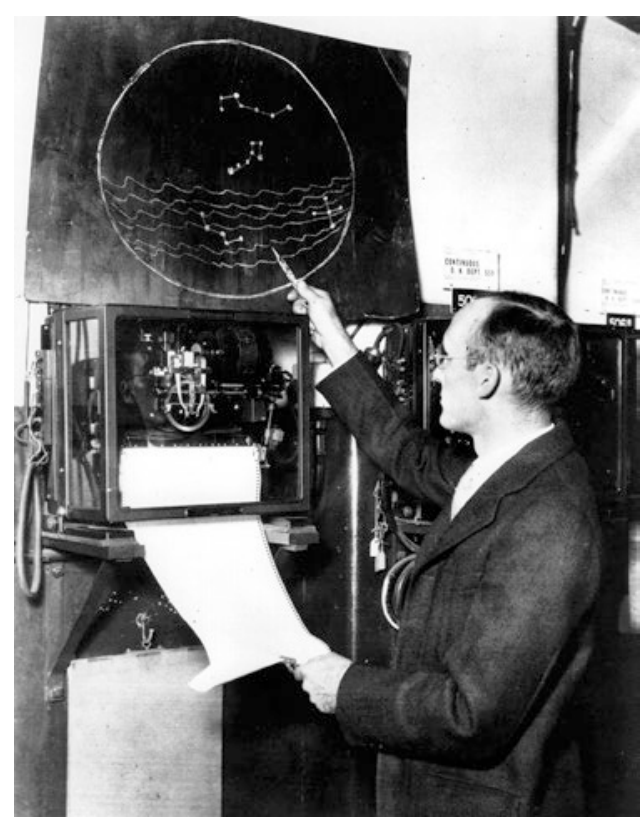

At the April 1932 Washington meeting of the US National Committee for the International Union of Radio Science (URSI), Jansky presented a paper on "Directional Studies of Static on Short Waves," 12 which he later published in the Proceedings of the Institute of Radio Engineers (Proc. IRE). In this, the first of his three classical papers, Jansky (1932) described in some detail his antenna and receiving system and reported that he had found three distinct groups of static.

The first group is composed of the static received from local thunderstorms and storm centers. Static in this group is almost always of the crash type. It is very intermittent... The second group is composed of very steady weak static coming probably from [ionospheric] refractions from thunderstorms some distance away. The third group is composed of a very steady hiss type static the origin of which is not yet known.

Jansky then goes on to discuss the crash type static in some detail, but adds,

The static of the third group is also very weak. It is, however, very steady, causing a hiss in the phones that can hardly be distinguished from the hiss caused by [receiver] noise.

He remarks that he did not recognize this third type of static until January 1932, but he was able to go back to reexamine his earlier data and recognized that 
the direction of arrival of this static coincided with ... the direction of the sun. However, during January and February, the direction has gradually shifted so that now [March 1] it precedes in time the direction of the sun by as much as an hour.

Still assuming that the source of static was terrestrial, and not having any background in astronomy, Jansky continued to speculate that the hiss type static might be related to the Sun, and that the change in apparent direction might somehow be due to the Sun's changing declination after the winter solstice. He concluded, however, that, "the data as yet cover only observations taken over a few months and more observations are necessary before any hard and fast deductions can be drawn."

Throughout 1932, Jansky meticulously continued his observations. Indeed, after the summer solstice when the Sun reached its northern declination limit, instead of changing direction the shift in apparent position of the star noise continued. According to Southworth (1956) Jansky discussed his results with many of his associates, including his supervisor, Friis, Southworth, Edmond Bruce, Al Beck, Art Crawford, and probably most importantly, Melvin [Mel] Skellett. Skellett, who was a close friend of Jansky's, was studying for his PhD in astronomy at Princeton. He apparently recognized the sidereal nature of Jansky's data and advised Jansky to look at elementary astronomy text books. Jansky studied these text books and mastered the trigonometric transformations between terrestrial and celestial coordinates. He went back and reexamined his data, and on 21 December 1932 he wrote to his father,

I have taken more data which indicates definitely that the stuff, whatever it is, comes from something not only extraterrestrial but from outside the solar system.

It comes from a direction that is fixed in space.

Karl apparently fully recognized the implications of his findings. Showing the same competitive spirit that his colleagues associated with his sports and bridge activities, he continued, "I've got to get busy and write another paper right away before someone else interprets the results in my other paper in the same way and steals my thunder from my own data." In an 18 January 1933 letter, he backed off somewhat, writing, "I have data which shows conclusively that the hiss type static comes from a direction which I know at least lies in a plane fixed in space and I think the direction is fixed in that plane but I am not sure of that as yet."13

Around this time, Karl's work was disturbed by a move to a new home in Little Silver with his wife and baby daughter, and an announced reorganization of Bell Labs with a threatened 30 percent cut in the engineering staff. He noted that a close friend and former roommate who had behaved "independently," but who had recently become a father and purchased a home was let "out." 14 This may have unnerved Jansky, who commented on the low morale at the lab and queried his father about possible teaching jobs at the University 
of Wisconsin or elsewhere. However, Karl escaped the layoffs and was able to present his remarkable results at the annual meeting of the US National Committee for URSI, which was held in Washington DC on 27 April 1933. Karl described URSI to his family as "an almost defunct organization ... attended by a mere handful of old college professors and a few Bureau of Standards engineers." 15 "Beside this," Karl continued, "Friis would not let me give the paper a title that would attract attention but made me give it one ["A note on hiss type atmospheric noise"] that meant nothing to anybody but a few who were familiar with my work."

Karl's brother, Moreau, who himself was an influential leader of the URSI National Committee, was clearly impressed by his younger brother's paper and apparently convinced the AT\&T publicity department to issue a press release describing Jansky's star noise. ${ }^{16}$ As Karl wrote to his father, "the science editors of the N.Y. papers were alert enough to realize the importance of the subject and yesterday afternoon pestered the life out of the publicity department." The 5 May 1933 edition of the New York Times featured an "above the fold" article titled, "New Radio Waves Traced to the Centre of the Milky Way." Other headlines on the same front page ominously referred to the anticipated invasion of China by Japan and Nazi threats at the French border. The following day, the Times "Week in Science" section noted that Jansky's star noise was at the extreme end of the same electromagnetic spectrum that included the familiar visible spectrum that was the basis of all previous astronomical knowledge. On 15 May, the NBC Blue Network, which later became the ABC, interviewed Jansky and played three 10-second segments of Jansky's star noise received at Holmdel and sent over the AT\&T Long Lines. In describing his star noise during his interview, Jansky explained,

The observations show definitely that the maximum of hiss comes from somewhere on the celestial meridian designated by astronomer as " 18 hours right ascension." ... But my measurements further show that the radio hiss comes from a point on that 18-hour meridian somewhat south of the equator, that is at about minus ten degrees in declination ... that seems to confirm Dr. Shapley's calculation that the radio waves seem to come from the center of gravity of our galaxy. ${ }^{17}$

Jansky's extraordinary discovery was reported in national and international newspapers as well as in the 15 May edition of Time Magazine. The publicity generated by the media exposure resulted in the usual crank letters. As he wrote to his father, "I received a letter today from spiritualist [who] thinks I am receiving messages from the 'other' world [and] from some crank mathematician [who] advises me to watch for numerical messages based on the factor ' 2 , 4, 8 etc' indicating a 'superior' intelligence." 18 There is little doubt that Karl was aware of the impact of his discovery and that he relished the publicity. In October, he gave an invited lecture at the American Museum of Natural History in New York with the provocative title, "Hearing Radio from the Stars." 
Perhaps sparked by the attention resulting from the New York Times article and realizing that his published Proc. IRE paper incorrectly suggested that the hiss type noise originated in the Sun, on 8 May, Karl sent a short note to Nature, titled, "Radio Waves from Outside the Solar System," (Jansky 1933a). In this paper, published on 8 July, Jansky states, "the direction of arrival of this disturbance remains fixed in space, that is to say the source of this noise is located in some region that is stationary with respect to the stars." He goes on to give the direction of the radio noise as "right ascension of 18 hours and declination of - 10 degrees." In a paper meant for a more popular audience, Jansky (1933c) confidently used the more specific and provocative title, "Electrical Phenomena that Apparently Are of Interstellar Origin."

Jansky originally had wanted to announce his discovery at the Chicago IRE meeting which was held in June 1933, but Friis had rejected his request and "insisted" that he give the talk instead at the April URSI meeting. Following the attention resulting from the New York Times article and the NBC broadcast, at Karl's request, his brother Moreau again stepped in to use his influence to get Karl invited to the June IRE meeting. ${ }^{19}$ At this point, ignoring Friis' reservations, but with the encouragement of more senior Bell Labs management, Karl decided on his own to change his title "to suit myself." ${ }^{20}$ His IRE talk was published in the Proc. IRE (Jansky 1933b) as his now classic paper on "Electrical Disturbances Apparently of Extraterrestrial Origin." For the benefit of the IRE engineering readers, he first reviewed the relationship between terrestrial and astronomical coordinate systems and the difference between solar and sidereal time. In his introductory summary, he concludes "that the direction of arrival of these waves is fixed in space, i.e., that the waves come from some source outside the solar system," and here he gives this direction as the "center of the huge galaxy of stars and nebulae of which the sun is a member." Following his talk, Karl sent a copy of his paper to the well-known Princeton astronomer, Henry Norris Russell, and arranged to meet with Russell to discuss the meaning of his star noise.

For the next two years, Jansky was apparently preoccupied with other research activities, but found the time to analyze his data more carefully. In July 1935, he again gave a talk at the Annual IRE Convention in Detroit, and was able to report that the radio emission came from the entire galactic plane with the strongest radiation coming from the Galactic Center. ${ }^{21}$ In his third Proc. IRE paper, following his Detroit talk, Jansky (1935) explained that the noise peaks correspond to those times when the antenna beam is oriented along the plane of the Milky Way, and second, that the largest peak comes from the "that section of the Milky Way nearest the center." Although he concluded that the "most obvious explanation of these phenomena ... is that the stars themselves are sending out these radiations," he did not exclude the possibility "that the waves that reach the antenna are secondary radiations caused by some form of bombardment of the atmosphere by high speed particles which are shot off by the stars." In this paper, Jansky also made the first attempt to understand the physics behind his star noise noting that "one is immediately struck by the 
similarity between the sounds they produce in the receiver headset and that produced by the thermal agitation of electrical charge. In fact the similarity is so exact," he explained with some prescience, "that it leads one to speculate as to whether or not the radiations might be caused by the thermal agitation of charged particles." 22

Jansky also commented on the important contrast between the optical and radio sky, pointing out that while visually the Sun appears brighter than the radiation from all the stars combined, the reverse was true at radio wavelengths. He realized that if all the stars in the Milky Way are like our Sun, that could not explain his observed noise from the Milky Way. He speculated that "a possible explanation ... [is] that the temperature of the sun is such that the ratio of energy radiated by it on the wavelengths studied to that radiated in the form of heat and light is much less than for some other classes of heavenly bodies found in the Milky Way." It is clear from this third Proc. IRE paper and from his short notes in Nature and Popular Astronomy (Jansky 1933a, c) that Jansky was not satisfied just to have solved the problem of short wave radio noise, but he wanted to understand and disseminate the implications to the astronomy and astrophysics communities as well as to the broader public.

More than a decade later, URSI President Sir Edward Appleton commented in his 1948 Presidential address, "Jansky's work seems to me to have all the characteristics of a fundamental discovery. In the first place he recognized something that was unexpected. In other words, he discovered something when he was actually looking for something else. But he then went further, for he recognized his unexpected result as being significant. And pursued it with zeal until much of its true meaning emerged." ${ }^{23}$ As John Kraus (1981) later noted, Jansky's system contained all the elements of future radio telescopes: (1) a directional antenna, (2) a broad band low noise receiver, and (3) a radio quiet site. Somewhat later, Grote Reber (1988) added, "Reading Karl Jansky's articles is an enlightening example of how a first class human mind works, and how one hypothesis is discarded for another as more evidence rolls in."

Woodruff Sullivan (1978) later reanalyzed Jansky's data from 16 September 1932 , and presented it in a modern form as a contour map in galactic coordinates (Fig. 1.4). Sullivan's map, which displays the concentration along the galactic plane and the maximum toward the Galactic Center, also shows the maximum later recognized as the Cassiopeia A supernova remnant as well as evidence for the Cygnus A/Cygnus X complex.

The Later Years In order to enhance Bell Labs' transatlantic radio communications capability, Friis developed the highly directional Multiple Unit Steerable Array (MUSA) rhombic antenna (Friis and Feldman 1937). ${ }^{24}$ In his continuing study of short wave noise and radio wave propagation, Jansky $(1937,1939)$ used MUSA to show that in the absence of manmade interference, the sensitivity of short wave radio systems was limited by interstellar noise, and not by receiver circuit noise. During this period, he also tried to use the MUSA system with a goal of measuring the frequency dependence of his "star noise." The 


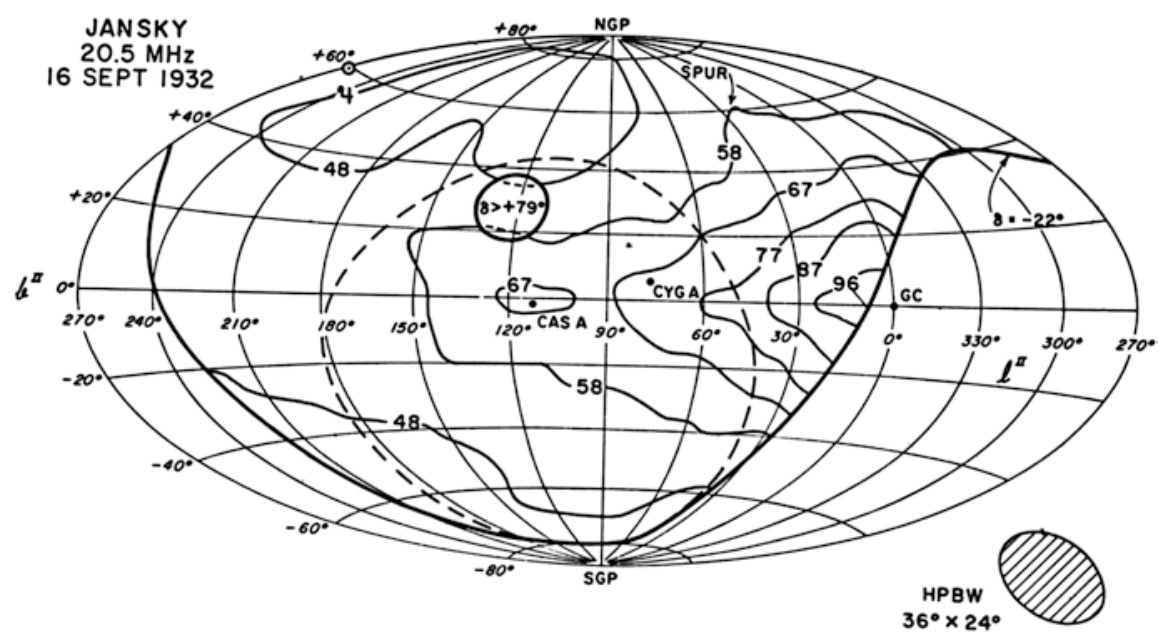

Fig. 1.4 Contour map of the 14.6 meter cosmic radiation derived by W.T. Sullivan III from observations made by Karl Jansky on 16 September 1932. The contours are normalized to a peak value of 100 corresponding to brightness temperature of $100,000 \mathrm{~K}$. The dashed line shows the track of a typical 20 min rotation of the antenna. Credit: Courtesy of W.T. Sullivan III

published results were inconclusive, most likely due to the increasing solar activity and the corresponding D-layer ionospheric attenuation, but also to broadband interference generated by nearby diathermy machines. Al Beck, who worked with Jansky at the time, later noted that the cosmic signal was strongest at the longer wavelengths ${ }^{25}$ but there is no contemporaneous record or documentation that Jansky or Beck had understood the nonthermal nature of the star noise. Interestingly, 1932 was near the bottom of the sunspot cycle. Had Jansky done his pioneering work five years earlier or five years later, the ionosphere probably would not have allowed him to detect extraterrestrial radio noise at $21 \mathrm{MHz}$ (15 meters), although he would then probably have detected radio emission from the active Sun.

Although AT\&T was quick to exploit the popular interest in Jansky's discovery, further investigation of "star-noise," other than as a noise floor, did not rank high in AT\&T's priorities. Even during the critical period of 1932 and 1933, Jansky did not work full time on star noise, as his laboratory notebook shows considerable effort spent on understanding the direction of arrival of short wave radio transmissions. As noted by George Southworth (1956), "Somewhat later he was assigned to other duties and his work on radio astronomy came to an end. His interest nevertheless continued."

For some years after 1935, Jansky's “merrygoround" was used by Beck (1984) and others for testing antennas, but it ultimately fell into disrepair and the remnants were destroyed. Following a suggestion by Grote Reber ${ }^{26}$ to Southworth, and with the encouragement and support of Al Beck, in 1964, a 
replica of Karl Jansky's antenna was erected at the entrance of the NRAO Green Bank Observatory. Years later, former Bell Labs scientists J. Anthony (Tony) Tyson and Robert (Bob) Wilson located the site of the original antenna at Holmdel, and on 8 June 1998, Bell Labs dedicated a memorial model antenna on the site of Jansky's original array.

With the rapidly deteriorating international situation in the late 1930s, Jansky became increasingly involved in classified defense work, particularly related to electronic detection of submarines, for which he received an ArmyNavy citation. Following the end of World War II, he worked on the emerging AT\&T microwave repeater network for long distance telephone communication and followed with interest the rapidly developing field of radio astronomy. After the Bell Labs invention of the transistor in 1947, Jansky was one of the first to use transistors to build low noise preamplifiers and received several patents on a radio direction finder or sextant based on the radio emission from the Sun which was later developed by the Collins Radio Co. for the Naval Research Laboratory. His deteriorating health limited his activities and, after a series of strokes, on 14 February 1950, Jansky succumbed to his long illness and died at the young age of 44 . This was a year before the discovery by Ewen and Purcell (1951) of the $21 \mathrm{~cm}$ hydrogen line at Harvard (Chap. 2) brought radio astronomy to the attention of the broad astronomical community. Just before his death, Karl was transferred to a small group under George Southworth that also included Russel Ohl, who played a prominent role in the Bell Labs development of the transistor.

Controversy John Pfeiffer was a free-lance author who wrote the first popular book about the new science of radio astronomy called The Changing Universe: The Story of the New Astronomy. Prior to writing his book, Pfeiffer traveled to the major observatories and laboratories working in radio astronomy. In 1954 he visited Bell Laboratories and spent a day talking with Harald Friis and members of his Radio Research Section about Karl Jansky and his discovery of interstellar radio emission. In his book, Pfeiffer (1956, p. 17) claimed that Jansky "did all he could to convince his associates and superiors that the work was worth pursuing for practical reasons. But his arguments failed to produce results." Pfeiffer further incited the issue stating, "Rarely in the history of science has a pioneer stopped his work completely, at the very point where it was beginning to get exciting. Yet Jansky did just that.”

In his review of Pfeiffer's book in Science, Frank Edmondson (1956), a wellknown optical astronomer, writing from the National Science Foundation, threw coals on the fire when he hinted that "Jansky's failure to secure support for continued pure research at Bell Laboratories" may have led the US to be "lagging far behind other countries in the development of radio astronomy." This generated a strong rebuttal from Karl's associate J.C. Schelleng who wrote to the editor of Science, Graham DuShane, ${ }^{27}$ arguing that, "It is news to Mr. Jansky's associates at Holmdel to be told that he tried seriously to continue the work and failed .... If the astronomers showed any excitement at the time, we 
saw no sign of it." Schelleng went on to point out that after reading Grote Reber's paper, Jansky "cheerfully" noted that "he had skimmed the cream," and "showed no sign of disappointment."

Karl's brother, C.M. (Moreau) Jansky, Jr. (1958) further incited controversy when he wrote the introductory article in the Proc. IRE special issue on radio astronomy describing his brother's discovery of extraterrestrial radio emission. In his paper, Jansky wrote that, "his superiors transferred his activities to other fields. He would have preferred to work in radio astronomy." Picking up on Jansky's remarks, the popular magazine, Readers Digest, reported, "Astronomers were slow to recognize [Karl] Jansky's discovery, [and that] his boss told him to stick to ordinary static, and reluctantly he did so." (Kent 1958). In a letter to Karl's brother Moreau, ${ }^{28}$ and in a later paper in Science, Friis (1965) denied that this was true, and said Karl "was free to continue work on star noise if he had wanted to," and that Karl had never indicated to him "a desire to continue his star noise work." Moreover, noted Friis, during this period there had been no interest or encouragement from astronomers and it was not clear in what directions such research should go and what kind of equipment was needed. Essentially, he argued that Karl felt that having found the source of noise, he had completed that particular project. Much later, on several occasions Friis $(1965,1971)$ commented that Jansky should have received a Nobel Prize for his discovery of cosmic radio emission. ${ }^{29}$

Moreau reacted to Friis by writing to Karl's widow, Alice, to seek her comments. ${ }^{30}$ Alice responded,

Harald says that Karl never expressed to him a desire to continue work on his star noise. How incredible, how preposterous, how positively unbelievable. Periodically, over the years that Karl worked under Friis, he would come home and say, "Well, Friis and I had a conference today to discuss what my next project should be, and, as usual, Friis asked what I'd like to do, and as usual, I said, 'You know I'd like to work on my star noise,' and as usual, Friis said, 'Yes, I know, and we must do that some day, but right now I think—and—is more important, don't you agree?"”31

Moreau decided not to respond to Friis, but thanked Alice for "substantiating the statements made in the last two paragraphs of my paper," and added, "I have been informed that quite a number of people have expressed the opinion that they are glad that I said what I did." 32 It is perhaps significant that while Friis portrays a close personal relationship with Jansky, in all of his letters to his parents, Jansky always referred to "Friis," or "Mr. Friis," never using his first name. To Karl and Alice's children, Anne Moreau and David, they were Uncle Harald and Auntie Inge. However, at least at work, Friis apparently just called Karl "Jansky."

Radio astronomy again came to the forefront at Bell Labs in 1965 following the detection of the cosmic microwave background by Arno Penzias and Bob Wilson (Penzias and Wilson 1965). Bell Labs wanted to clarify the growing 
and clearly embarrassing controversy over Jansky. Ray Kestenbaum of their Public Relations Department conducted a series of interviews with Jansky's boss Harald Friis, his colleagues Al Beck, John Schelleng, and Art Crawford, as well as Karl's brother Moreau. ${ }^{33}$ Everyone from Bell Labs described Karl as friendly, modest, and easy to get along with. They also noted that he was very competitive in sports and bridge. All, especially Friis, denied ever hearing any expression from Karl that he felt constrained from pursing his star noise research, and they all noted that it was not clear to any of them, Karl included, what might be the next steps. Karl, they maintained, was never "stopped" from pursuing further work on star noise, that he was happy with his work, that his primary research interests were in antennas and receiver noise, and that he enjoyed working at Bell Labs.

Although George Southworth was not interviewed, Kestenbaum later wrote to Southworth for his views on this controversial issue. His initial response was equivocal, ${ }^{34}$ but recalling Southworth's (1956) earlier remark that Jansky "was assigned to other duties," Lloyd Espenschied, then retired from a senior management position at Bell Labs, later wrote to Southworth commenting on a paper in the Bell Labs Record that claimed that Jansky did not continue his star noise research "due to a lack of theoretical understanding ... and by the inability to detect radio noise from the Sun." 35 "I wonder who concocted this fabrication as the 'cover-up' it is?" wrote Espenschied, "I remember very well how Karl's foundling babe was left out in the cold, much to his distress, simply because it was regarded as not being pertinent to the Bell system."

Southworth responded with a brief factual summary of Jansky's career at Bell Labs, his own satisfaction with Jansky's productivity at Bell Labs, but concluded that, "Other matters like the handling of Jansky's case bespoke many unpleasant, if not indeed tragic experiences. Most of us, without knowing why, thought intuitively that he had not been dealt with fairly." ${ }^{36}$

Were Friis and the other Bell Labs staff who were interviewed by Kestenbaum just trying to protect the reputation of the Labs? Or were Southworth and Espenschied expressing broader pent up dissatisfaction with the Labs? And were Moreau and Alice carried away with family loyalties and a desire to preserve and enhance Karl's reputation?

Contemporaneous insight to what happened between Friis and Jansky is documented in the series of Karl's letters to his parents which were often critical of Friis and do not support Friis' position. Friis was described by another Bell Labs employee, Russel Ohl, as a "dictator [who] wanted things done exactly the way he said." ${ }^{37}$ When Karl complained to his father about the title of his 1933 URSI paper, he went on to mention that his brother Moreau reported that the IRE Board of Directors considered that "my paper was the outstanding paper of the Washington meeting," ... and "that they all agreed that the title to the paper was too commonplace [a direct slap at Friis]." Karl's father expressed sympathy, but cautioned Karl, "Do not antagonize him. Keep on consulting him as formerly. He is your boss and loyalty ultimately pays no matter whether it is deserved." 38 
A month later, Karl wrote "I have not the slightest doubt that the original source of these waves whatever it is or wherever it is, is fixed in space. My data proves that, conclusively as far as I am concerned. Yet Friis will not let me make a definite statement to that effect but says I must use the expression 'apparently fixed in space' or 'seems to come from a fixed direction' etc. etc. ... But I suppose it is safer to do what he says." ${ }^{39}$ Following the announced layoffs in the spring of 1933, Karl wrote to his parents, "Nothing has happened yet at the labs in the matter of firing some of the engineers. The ax is still hanging over our heads.... What a $\mathrm{h}-1$ of a way to run an organization." 40

In January 1934 , he wrote ${ }^{41}$

I now have what I think is definite proof that the waves come from the Milky way. However, I am not working on the interstellar waves any more. Friis has seen fit to make me work on the problems and methods of measuring noise in general. A fundamental and necessary work, but not very interesting as the interstellar waves, nor will it bring me near as much publicity. I'm going to do a little bit of theoretical research of my own at home on the interstellar waves however.

Grote Reber (1982) later reported that toward the end of World War II, he had met Jansky during a Washington URSI meeting, and that over lunch, Jansky had mentioned that in $\mathbf{1 9 3 6}$ he wrote a memorandum proposing construction of a 100 foot diameter transit dish operating at $5 \mathrm{~m}$ wavelength $(60 \mathrm{MHz})$. Apparently, as Jansky explained to Reber, he had been informed, "that the proposal was outside the realm of company business." 42 However, no record of such a proposal has been found in the Bell Labs Archives or among any of Karl's existing personal papers and letters.

To better appreciate the situation surrounding Jansky's important discovery, it is important to understand the political, social, and economic revolutions that were ravaging the world in 1933 and that only became worse over the following decade. Only a few months earlier Adolph Hitler had become Chancellor of Germany, and two days later he dissolved the German Parliament, starting a series of edicts and decrees that within a few years would lead to global catastrophe. Just six weeks before Jansky's announcement of his detection of radio noise from the Milky Way, Franklin Delano Roosevelt became the 32nd President of the United States, and promptly closed the banks. Later that year the United States would abolish the gold standard and prohibition; Babe Ruth would hit a home run to win the first major league all-star baseball game; the world's first drive-in theater would open in New Jersey; and the infamous John Dillinger would rob his first bank. Erwin Schrödinger and Paul Dirac won the 1933 Nobel Prize in Physics for their development of quantum mechanics, and the astronomy community was still absorbing the implications of Hubble's expanding Universe (Hubble 1929) with its emphasis on building large new optical telescopes to detect ever more distant galaxies.

The US and the world were in the throes of a major depression. It is said that fully one third of the US population was out of work. Rather than lay off 
staff, Bell Labs had cut its work week to four days, although many staff members, including Jansky, continued to work five days a week while getting paid for four. Bell Labs employees worried about their livelihood and many explored other opportunities. Anticipating the potential prospects for more time to pursue his research, but conscious of his chronic illness and uncertain life expectancy, Karl asked his father about possible positions at the University of Wisconsin or even teaching at a high school. With encouragement from Alice he applied for a position at Iowa State University, but was unsuccessful, and there is no evidence that he again seriously entertained leaving Bell Labs. By 1944, to meet the demands of the defense effort, Jansky was working overtime and enjoying the extra pay, which he needed to meet his increasing medical expenses.

While it is likely that Harald Friis did not encourage further work on Karl's star noise to the extent that Karl might have wished, neither did he apparently discourage Karl, other than by assigning him new tasks. Nevertheless, it seems Karl was not unhappy with his work or with Bell Labs. Aside from the critical comments to his father, he apparently did not push Friis hard to continue his star noise research. He understood the corporate nature of his employer and the constraints imposed first by the Depression, then by the War, as well as considerations of his health and the well-being of his young family. So while he may have shared his frustrations about Friis with his family, his father, and his wife, he also respected Friis as his boss, as well as valued him as a personal friend. It is also important to recognize that Friis, himself, was under pressure from senior management and directly from defense contractors to deliver on a multitude of contracts with limited staff, and Jansky was surely aware of this. ${ }^{43}$ As many of his colleagues emphasized, the important thing may not be why Karl stopped his pioneering work after receiving broad national and international recognition, but that he accomplished so much in such a short time.

Recognition Although Karl Jansky's discovery of galactic radio emission did not have an immediate direct impact on astronomy, the discovery of radio noise from the Milky Way was widely recognized and discussed among astronomers as well as by the general public. Karl's father reported being at a talk by the University of Illinois astronomer Joel Stebbins, who drew attention to Karl's discovery. ${ }^{44}$ Harlow Shapley, Director of the Harvard College Observatory (HCO), even wrote to Jansky asking for copies of his IRE paper and Jansky reported that they had a vigorous discussion at the Harvard Physics Department about Jansky's work. ${ }^{45}$ At a later meeting in New York, Shapley asked about the cost of repeating the experiment, but was discouraged by Jansky's initial response. Subsequently, however, Jansky realized that the equipment he had used was originally built for another purpose, and he felt that it would be possible to confirm his results at much lower cost by using a commercial short wave receiver. But, apparently, by this time, Shapley had either lost interest or was discouraged by Harvard's unfamiliarity with anything to do with radio or electronics. 
Two Harvard astronomers who thought hard about Jansky's star noise were graduate student Jesse Greenstein, and Fred Whipple, then a young Harvard faculty member. They had read Jansky's papers, and tried to interpret the radio noise as thermal radiation from cold dust (Whipple and Greenstein 1937). However, Jansky's star noise exceeded their model predictions by a factor of 10,000 (Sullivan 2009, p. 41). Henyey and Keenan (1940) tried to interpret the observations in terms of free-free emission from ionized hydrogen, and remarked, "in the case of Jansky's data the discrepancy is serious." Although these papers were unsuccessful in trying to explain the nature of the radio signals as thermal emission from interstellar dust, they underscored the need for unconventional nonthermal interpretations of cosmic radio emission. It would be another 15 years before the Russian scientists, Vitaly Ginzburg (1951) and Iosef Shklovsky (1952) would explain that the nonthermal galactic radio emission is due to synchrotron radiation from ultra-relativistic electrons moving near the speed of light in a weak magnetic field. ${ }^{46}$

At Caltech, Professor R.M. Langer was inspired by Jansky's papers to consider possible mechanisms to explain the observed radio emission from the Milky Way, and gave a talk to the American Physical Society proposing that Jansky's star noise was the result of free electrons combining with ionized dust particles (Langer 1936). Langer's ideas did not make the New York Times but did appear on the front page of the 13 March 1936 edition of the Los Angeles Times.

So Jansky's discovery was well known to the scientific community, and was certainly not ignored by astronomers. They considered it interesting and even important. However, no one, Karl included, appreciated the extent to which other new discoveries would follow from further research using this new window on the Universe, or, with the exception of a few individuals like Grote Reber, what should be the next step.

In 1948, Jansky was nominated for the Nobel Prize in Physics by the German physicist Winfried Schumann, who was known for his research on lightning-generated extremely low frequency radiation. But this was before the explosive growth of radio astronomy in the 1950s and the importance of Jansky's work was not widely appreciated. Perhaps not coincidently, Appleton's presentation at the 1948 URSI General Assembly in Stockholm may have been intended to call the Nobel committee's attention to Jansky's achievements. After the meeting, Karl's widow, Alice wrote to Appleton thanking him for his recognition of Karl's work with a passing reference to the Nobel Prize ${ }^{47}$ Most likely, had he lived longer, Karl Jansky would have been recognized with the Nobel Prize, which eight other scientists have subsequently received for work in radio astronomy. ${ }^{48}$

In 1959, the new laboratory building at NRAO was named the "Jansky Laboratory" and, after a major upgrade, the NRAO Very Large Array, was rededicated in 2012 as the "Karl G. Jansky Very Large Array." (Sect. 7.8) At the 1973 IAU General Assembly held in Grenoble, France, the Commission on Radio Astronomy passed the following resolution. "RESOLVED, that the 
name 'Jansky, abbreviated 'Jy' be adopted as the unit of flux density in radio astronomy and that this unit, equal to $10^{-26} \mathrm{Wm}^{-2} \mathrm{~Hz}^{-1}$, be incorporated into the international system of physical units" (Contopoulos and Jappel 1974). Increasingly, the unit of Jansky has been used not only in the radio part of the spectrum, but at IR, optical, and X-ray wavelengths as well.

\subsection{Early Follow-Up to Jansky's Discovery}

Since Jansky did not follow up his historic discovery, it was left to others to exploit the new window on the Universe that Jansky had opened. At the University of Michigan, John Kraus (1984) and his colleague Arthur Adel tried to detect the Sun at $1.5 \mathrm{~cm}$ wavelength just a few months after Karl's New York Times announcement. About the same time, Caltech Physics Professor Gennady Potapenko read about Jansky's work, and in October 1933, just six months after Jansky's New York Times announcement, Potapenko gave a talk at the Caltech Astronomy and Physics Club on "The Work of the Bell Laboratories on the Reception of Shortwave Signals from Interstellar Space."

In the spring of 1936, Potapenko and his student Donald Folland tried to reproduce Jansky's work, using first a pair of small loop antennas on the roof of the Caltech Physics Lab. Their receiver was tuned to $20.55 \mathrm{MHz}$ (14.6 meters), close to the frequency used by Jansky, but due to ignition noise from passing automobiles they did not obtain any useful data. To get away from the noise of Pasadena, they moved their experiment out to the nearby Mojave Desert, where they fastened one end of a 35 foot wire to a 25 foot mast. One person walked the slanted wire around the pole to exploit the directivity of the arrangement while the other took data. Later Folland returned to his home in Utah, and in the summer of 1936 repeated the experiment. According to Jesse Greenstein, ${ }^{49}$ Potapenko and Folland were able to detect a maximum in the Sagittarius region and later a second maximum in Cygnus.

Based on the success of their simple experiment, Potapenko, along with Fritz Zwicky, proposed constructing a rhombic antenna on a rotating mount designed by Russell Porter. Zwicky (1969, p. 90 and 91) estimated the cost to be about $\$ 200$, although Greenstein later told Reber that it was more like $\$ 1000 .^{50}$ Zwicky and Potapenko tried to get funding from Caltech for their venture but were apparently turned down by Caltech President Robert Millikan, who, moreover, discouraged Potapenko from publishing his results. ${ }^{51}$ There is no evidence that either Potapenko, Russell, or Folland ever returned to radio astronomy, although Zwicky, who remained at Caltech as a Professor of Astrophysics until his retirement in 1968, later maintained informal contact with the young Caltech radio astronomers and students. Considering that Caltech, with its strong basic research background and significant technical, academic, and financial resources, either did not chose to build on Jansky's discovery, or did not have a clear vision of what to do, it is perhaps not surprising that the telephone company also did not seize the initiative. 
Around the same time, according to Grote Reber (1982), in 1936, Fred Whipple, at Harvard, "considered doing a test to confirm Jansky's discovery." His innovative plan was to put outriggers on the dome of the Harvard 60 inch telescope, then string wires around the ends of the outriggers as a rhombic antenna. When the dome was rotated, the antenna would scan around the horizon. However, the HCO Director, Harlow Shapley, was reluctant to support Whipple's proposed initiative and Whipple never pursued his plan.

Sullivan $(2009$, p. 113) discusses 1940 observations by John DeWitt, who had previously worked at Bell Labs and who, working alone, was able to detect galactic radio emission at $111 \mathrm{MHz}$ using a simple rhombic antenna. ${ }^{52}$ About the same time, Kurt Franz, working at the German Telefunkenen laboratories noticed an increase in the noise of his directional navigational system whose intensity shifted by four minutes a day. Franz (1942) knew about Jansky's work, and correctly realized that he had detected radio noise from the Galaxy.

\subsection{Grote Reber and Cosmic Static ${ }^{53}$}

Aside from the short experiments by Friis, by Potapenko and Folland, DeWitt, and Franz, the only known attempt to continue or expand on Jansky's discovery was by Grote Reber (Fig. 1.5), working by himself in Wheaton, Illinois. Reber had graduated in 1933 from the Armour Institute of Technology (now the Illinois Institute of Technology) with a degree in electrical engineering, specializing in the fledgling fields of electronics and communications. After graduation, he held a series of jobs with various Chicago companies, including

Fig. 1.5 Grote Reber in 1975 during one of his visits to Green Bank. Credit: NRAO/AUI/ NSF

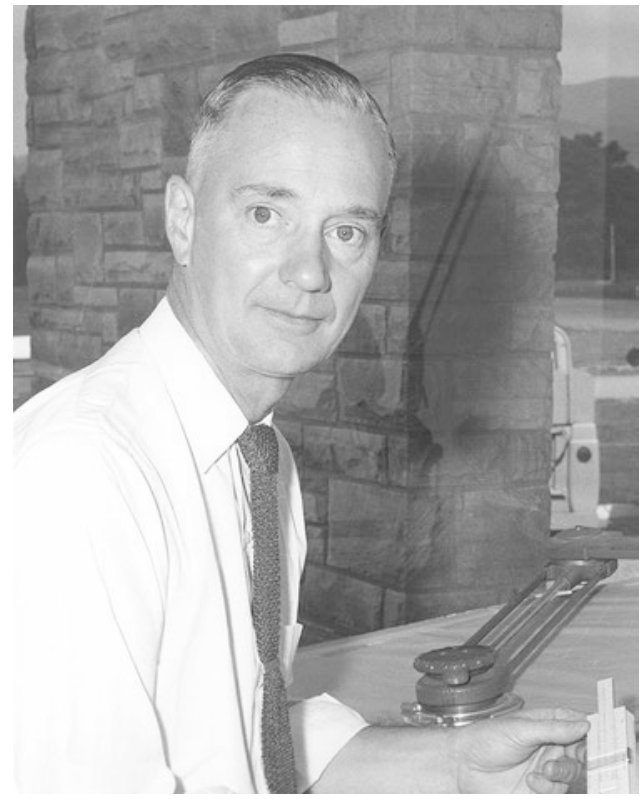


General Household Utilities (1933-1934), the Stewart-Warner Corporation (1935-1937), the Research Foundation of the Armour Institute of Technology (1939), and finally the Belmont Radio Corporation. Initially, he worked on developing broadcast receivers, but later worked on military electronics. His starting salary after graduation was $\$ 25$ per week. Reber enjoyed telling how his parents forgot to name him, so his birth certificate merely gives his name as "Baby Reber." Although he was called Grote by his parents, it wasn't until he was 20 years old that he officially had his name verified on a revised birth certificate by the authority of the Cook County Clerk, Richard E. Daley, who later became the infamous major of Chicago.

Reber (1958) later related that he had read Jansky's papers in the Proceedings of the Institute of Radio Engineers and had listened intently when Jansky's "star noise" was rebroadcast by the NBC Blue network. When he was only 16 years old, he obtained his amateur radio license, W9GFZ, signed by then Secretary of the Interior, Herbert Hoover. Reber (1958) recalled that in the late 1920s and 1930s, he noticed that if he connected an antenna to his receiver, the noise level would increase when the various receiver stages were tuned to the same frequency, but not when the antenna was disconnected. Probably he, as well as other radio amateurs, had detected Karl Jansky's galactic radio noise at $10 \mathrm{~m}$ wavelength, but did not realize this until many years later.

After contacting more than 60 countries with his amateur radio station, Reber was looking for new challenges. He was intrigued by the concept of cosmic radio emission, and in 1933, he wrote to Jansky to get more information about his work and to see if he could come to Bell Labs to work with Jansky ${ }^{54}$ but he was surprised and disappointed to learn that Bell Labs did not plan any further work in this area. Reber then contacted various observatories and university departments to see what they were doing, but like Jansky, he found little interest among the astronomers of the time who were busy with their own projects. He tried to interest Otto Struve and other astronomers at Yerkes Observatory, but they also showed little enthusiasm. As Reber later described it, “The astronomers were afraid, because they didn't know anything about radio, and the radio people were not interested, because it was so faint it didn't even constitute an interference-and so nobody was going to do anything. So I thought, well if nobody is going to do anything, maybe I should do something." 55

Working by himself for nearly a decade, Grote Reber relentlessly pursued his own investigations of Jansky's fundamental discovery and set the stage for the extraordinary developments in radio astronomy which occurred over the next half a century. Reber did not wish to merely confirm Jansky's work but wanted to address two fundamental questions that still motivate radio astronomers today: "How does the intensity at any wavelength change with position in the sky," and "How does the intensity at any position change with wavelength?" (Reber 1958, 1982). He recognized that the then conventional wire arrays were effectively monochromatic, so borrowing techniques used in optical astronomy, as he later related, "I consulted with myself and decided to build a 
dish." ${ }^{56}$ To supplement his background in engineering and to enhance his understanding of optics and astronomy, he took classes at the University of Chicago, including a course in astrophysics from Philip Keenan. As part of the requirements for Keenan's class, Reber prepared a survey paper titled "Long Wave Radiation of Extraterrestrial Origin," in which he discussed the results of Jansky, Friis and Feldman, and Potepenko. ${ }^{57}$

Cosmic Static Reber first experimented with a paraffin lens, but found that it was too heavy and too unwieldy ${ }^{58}$ During the summer of 1937, he took leave from his Chicago job, and using his own funds, designed and built a 32 foot parabolic transit dish in a vacant lot next to his mother's house. Except for the galvanized iron reflecting surface and fasteners, Reber constructed his antenna entirely out of wood. Like Jansky, Reber made use of scrapped parts from an old Model T truck as part of the elevation drive system. Curious neighbors could only speculate about the purpose of the unfamiliar structure rising in the small town of Wheaton, but Reber's mother found it a convenient place to hang her wash. Before her marriage, his mother, Harriet Grote, was an elementary school teacher. Among her seventh and eighth grade students at Longfellow School in Wheaton were Edwin Hubble and Red Grange, later to become a legendary football hero. Reber recalled that, as a teenager, Grange delivered ice to their home, and later he corresponded with Hubble to question the interpretation of redshifts. ${ }^{59}$

In April 1937, Reber wrote to Jansky asking about the gain of Jansky's equipment so that he could better estimate the sensitivity he would need to detect interstellar radio emission. ${ }^{60}$ Using his experience and skills as an electrical engineer and radio amateur, he designed, built, and tested a series of radio receivers which he placed at the focal point of his antenna, with the connecting wires running through a coal chute to his observing room in the basement of his mother's house. Although Jansky's work was carried out at a wavelength of $15 \mathrm{~m}(20.6 \mathrm{MHz})$ in the short wavelength band, Reber initially decided to observe at a much shorter wavelength of $9 \mathrm{~cm}(3300 \mathrm{MHz})$ which, at the time, was the shortest feasible wavelength for existing technology. At $9 \mathrm{~cm}$, he would get better angular resolution than Jansky had, ${ }^{61}$ and he also expected that, following the Rayleigh-Jeans radiation law, the celestial radio noise would be very much stronger at the shorter wavelength. ${ }^{62}$ His receiver, which he installed at the focal point of his antenna, used a homemade crystal detector followed by an amplifier.

By the spring of 1938 his antenna and $9 \mathrm{~cm}$ receiver were completed, but Reber was unable to detect any radio noise from the Galaxy, from several bright stars, nor from the Sun, the Moon, or the nearby planets. Although his observations gave negative results, Reber $(1958,1982)$ was able to draw the important conclusion that "the celestial radiation did not conform to the Rayleigh-Jeans Law." He rebuilt his receiver operating at the longer wavelength of $33 \mathrm{~cm}(910 \mathrm{MHz})$ where more sensitive and more stable instrumentation was available, but still he had no success. Undaunted, he built a new 


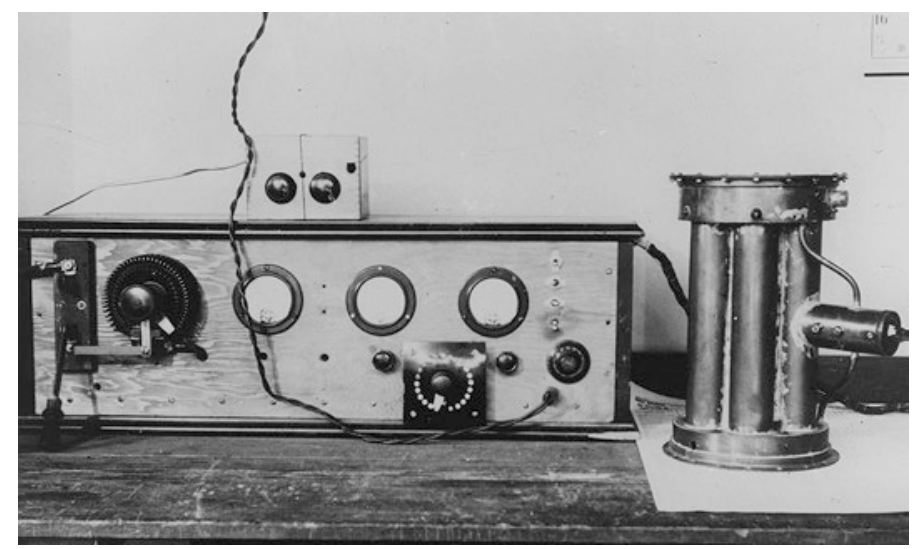

Fig. 1.6 Some of Reber's Wheaton equipment used to study cosmic radio emission. On the left is his receiver monitor and control system. On the right is his $160 \mathrm{MHz}$ amplifier. Credit: NRAO/AUI/NSF

receiver to operate at $1.9 \mathrm{~m}(160 \mathrm{MHz})$, where he used a newly developed RCA tube as a radio frequency amplifier to give better sensitivity (Fig. 1.6). Finally, in the spring of 1939, just a few months before the start of World War II, on his first night of observing with his newest receiver, Reber succeeded in detecting Jansky's galactic radio noise at $1.9 \mathrm{~m}$ wavelength, which he called cosmic static.

While working to develop military electronics in Chicago, Reber continued to make 1.9 meter observations at home in Wheaton. Attempts to detect radio emission from a few bright stars such as Vega, Sirius, and Antares, or Mars as well as the Sun were unsuccessful, and he concluded that there was little correspondence between the brightness of the sky at radio and optical wavelengths. Grote's younger brother, Schuyler, who was a student at the Harvard Business School, put Grote in contact with Fred Whipple and Harlow Shapley at the Harvard College Observatory. ${ }^{63}$ Although Whipple expressed interest in Reber's accomplishments, ${ }^{64}$ Shapley, who had already been in contact with Jansky several years earlier, remained reluctant to get involved with something that no one at Harvard knew anything about, and claimed that they could not start any new activities as they were already over-committed to other programs.

Reber submitted the results of his findings in a short paper titled "Cosmic Static" to the Proc. IRE where Jansky had published most of his pioneering papers. However, also wanting to reach out to astronomers, Reber sent a similar paper with the same title to the Astrophysical Journal $(A p J)$. The editors of both journals questioned the validity of his interpretation of Jansky's results, although the Proc. IRE promptly accepted the paper for publication in the full form as submitted (Reber 1940a). The second paper was received with skepticism by Astrophysical Journal editor, Otto Struve, who asked Bart Bok from Harvard to act as the referee. According to Jesse Greenstein, by then a young 
astronomer at the Yerkes Observatory, since Reber had no academic connection and unclear credentials, his paper produced a flurry of excitement at the Astrophysical Journal editorial offices at the Yerkes Observatory located north of Chicago. ${ }^{65}$ Reber (1982) later commented that since the astrophysicists didn't understand how the radio waves could be generated, they felt that "the whole affair was at best a mistake and at worse a hoax." ${ }^{66}$ At various times, Bart Bok, Otto Struve, Chandrasekhar, Philip Keenan, Jesse Greenstein, and Gerard Kuiper traveled to Wheaton to evaluate Reber's radio observations and equipment and also to evaluate Reber. As later claimed in a footnote by Reber (1982),

Otto Struve didn't reject my $160 \mathrm{MHz}$ paper. He merely sat on it until it got moldy. I got tired of waiting, so I sent some other material to the Proceedings of the IRE. It was published promptly in the February, 1940 issue [Reber 1940a]. From a much slower start, this beat the ApJ by four months. During the early days of radio astronomy, the astronomy community had a poor track record. The engineering fraternity did much better!

Bart Bok cautioned Struve that he could not afford to turn down the paper because it might "be a great success" (Levy 1993, p. 45). Following an exchange of correspondence with Philip Keenan, Reber's paper was finally published as a short note in the $A p J$ (Reber 1940b) along with the companion paper by Henyey and Keenan (1940) that discussed Jansky and Reber's data in terms of free-free emission from interstellar ionized hydrogen. In a later paper, sent to Proc. IRE, Reber (1942) published a more detailed report of his observations along with an extensive technical description of his instrumentation and a discussion of the impact of automobile ignition noise. As in his two previous papers, as well as those to follow, Reber again used the title, "Cosmic Static."

Among the few traditional astronomers who paid serious attention to Reber were Bengt Strömgren, who was then visiting Yerkes from Denmark, Otto Struve, Bart Bok, and Jesse Greenstein. Greenstein, also had been fascinated by Jansky's discovery of cosmic radio noise, and following his visit to inspect Reber's equipment, Greenstein and Reber became "moderately good friends." Grote Reber had forged the first lasting links between radio scientists and astronomers.

In 1940 with the encouragement of Otto Struve and Jesse Greenstein, Reber tried to negotiate with the University of Chicago and the Office of Naval Research (ONR) to move his antenna to a quieter site at the McDonald Observatory in Texas. But they could not agree on how to recover the cost of moving the antenna and operating a radio observatory in Texas. Greenstein and Struve suggested that Grote receive an appointment at the University of Chicago, so the university could administer the program and collect overhead costs from ONR. Reber insisted on preserving his independence and was not interested in working for the university. He explored the possibility of continuing his astronomy research while remaining an employee of his company, which he proposed would administer ONR funding, but this never came to fruition. 
Following the onset of World War II, Reber worked for a limited time at the Naval Ordnance Laboratory in Washington on the electronic protection of naval vessels. Due to a chronic hearing impairment, he was exempt from military service, and in 1943 Reber returned to Wheaton, to his job in Chicago, and to continue his radio astronomy investigations. Encouraged by his earlier success, he purchased a chart recorder to relieve him of the task of writing down the receiver output every minute. After making further improvements to his receiver and feed system, Reber went on to systematically map the $160 \mathrm{MHz}$ cosmic static. In order to keep the cost down, Reber's homebuilt antenna was limited to motion in elevation only. He laboriously observed the entire sky visible from Wheaton by changing the elevation of the antenna each day and letting the rotation of the earth scan the sky. Automobile ignition noise interfered with Reber's measurements, so he observed only at night. In the daytime Reber returned to his job designing broadcast radios at Stewart Warner in Chicago, where he commuted by train. The train journey to Chicago took one hour each way. ${ }^{68}$ Upon returning home, Reber would catch a few hours' sleep each evening before returning to his night's observing. On weekends, he analyzed his data, and converted his fixed elevation scans to a two dimensional map of the sky which he published in the Astrophysical Journal (Reber 1944).

Reber's maps (Fig. 1.7) clearly showed the pronounced maxima at the galactic center and what were later recognized as the Cygnus A/Cygnus X complex of sources, as well as the Cas A radio source (Reber 1944). As a result of his job as a radio engineer, Reber had access to state-of-the-art test equipment and the latest microwave vacuum tubes. In order to improve his angular resolution, he built new equipment to work to a shorter wavelength of $62 \mathrm{~cm}$ (480 MHz). Over a 200 day period in 1946 he repeated his observations at the
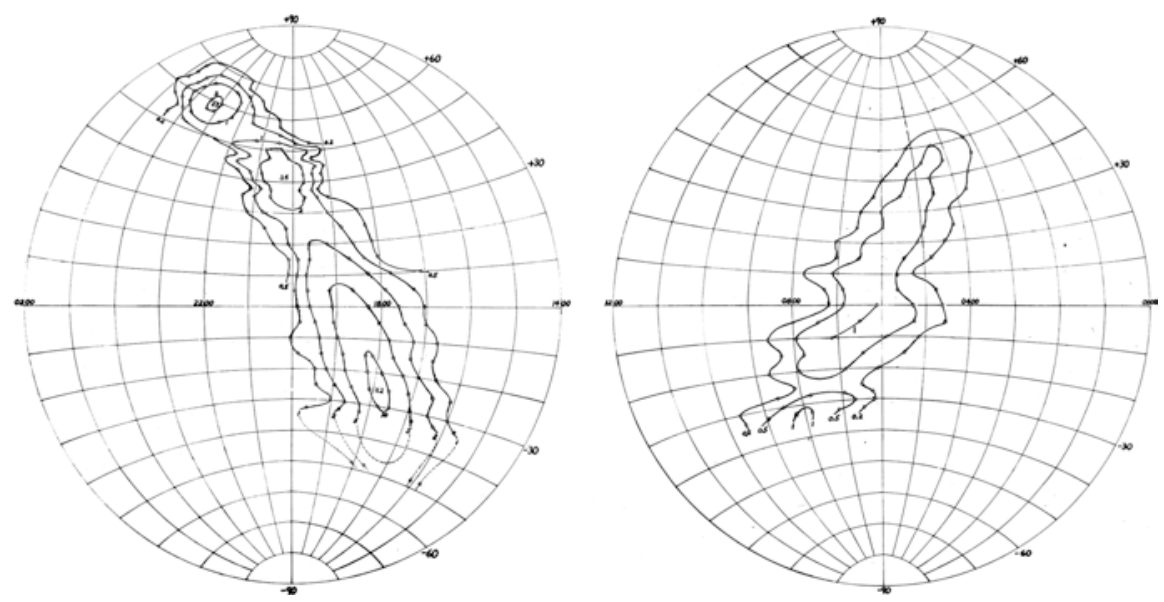

Fig. 1.7 Reber's (1944) contour maps of the $160 \mathrm{MHz}$ radio emission from the Milky Way Galaxy. Contours are shown as a function of right ascension and declination. Credit: NRAO/AUI/NSF 
shorter wavelength producing a more detailed map of the galactic radio emission which now also showed what was later recognized as the strong radio galaxy Cygnus A (Reber 1948a).

In his classic paper in the ApJ (Reber 1944), and later in the Proc. IRE (Reber 1948a), he noted that his radio maps trace the distribution of material in the Milky Way, commented on the evidence for spiral arms, and confirmed that the strongest radio noise was coming from the center of the Galaxy. $\mathrm{He}$ noted, with surprise and disappointment, that the $62 \mathrm{~cm}$ radiation was weaker than at 1.9 meters, indicating that the celestial radiation was nonthermal in origin. Later he remarked, "If the data doesn't fit the theory, change the theory not the data." 69

In 1947, Reber and Greenstein (1947) published what became the first review of radio astronomy. It included not only summaries of the pioneering investigations by Jansky and by Reber, but also covered the emerging postwar results now coming from radio scientists in England and Australia (Sect. 2.1). Trying to reach a broader audience, the following year Reber published an account of "Cosmic Radio Noise" in the semi-popular magazine RadioElectronic Engineering (Reber 1948b), followed by papers in Sky and Telescope (Reber 1949a), Scientific American (Reber 1949b), and in the popular Leaflets of the Astronomical Society of the Pacific (Reber 1950).

\subsection{Impact of Karl Jansky and Grote Reber}

Karl Jansky was the first person to look at the Universe outside the traditional visual wavelength band. Following the initial flurry of public interest and activity resulting from the 1933 New York Times article and NBC broadcast, there was little reaction or encouragement from the astronomical community. As evidenced by Potapenko, Folland, Zwicky, Greenstein, and Whipple, and perhaps Jansky himself, it was apparently not so much a lack of interest, but no one seemed to know what to do next. The gap between the radio scientists and the astronomers was just too great. Moreover, at the time the astronomical community was preoccupied with Edwin Hubble's announced expansion of the Universe and the need for larger optical telescopes to study more distant galaxies. Jansky's reports of radio emission from the Galaxy were received with interest, but did not really didn't fit into the then current mainstream astronomy. No one knew what to do next until Reber demonstrated radio observations could reveal new information about the Galaxy.

As John Pierce wrote on the occasion of the 1998 commemoration of the Jansky Memorial at Holmdel, "Jansky's work shows that very important phenomena can be disregarded when they don't find a niche in the science of their times." 70 As a result of the Depression, the threat of war, a chronic and ultimately fatal disease, and the commitment of AT\&T to its commercial and defense related obligations, Jansky spent the rest of his short career working in other areas. He became a recognized expert on noise, and was decorated for his defense work. Jansky's seminal papers in Proc. IRE were widely read throughout 
the world. In his third IRE paper (Jansky 1935) he commented, "this star static ... puts a definite limit upon the signal strength that can be received from a given direction at a given time and when a receiver is good enough to receive that minimum signal it is a waste of money to spend any more on improving the receiver." Later, scientists working on the development of radar facilities in the UK, as well as in Germany, recognized that their inability to lower the noise temperature of their meter wave radar, navigational, and communication systems was due to the Galactic radio emission which they referred to as "Jansky noise" (Lovell 1984).

Although he operated outside the mainstream of the astronomical community and often ridiculed conventional research, Grote Reber, unlike Karl Jansky, was recognized by the astronomy profession with most of its major prizes, including the Catherine Bruce Medal of the Astronomical Society of the Pacific, the prestigious Elliot Cresson Medal of the Franklin Institute, and the 1962 Russell Prize of the American Astronomical Society. Reber received an honorary Dr. Sc. Degree from Ohio State University, and in 1999 he was named by the Illinois Institute of Technology as a Man of the Millennium. In 1987, he was inducted into the DuPage County (Illinois) Heritage Gallery Hall of Fame, and was inducted posthumously to the National Inventors Hall of Fame in 2013.

Grote Reber was the world's first radio astronomer, and for nearly a decade the only person in the world devoting significant effort to this new field of astronomy. He went to great effort to demonstrate the importance of his work to the astronomical community. His maps of the radio emission from the Milky Way and his report of intense nonthermal radio emission from the Sun provided much of the incentive for the dramatic growth in radio astronomy following the end of World War II and also stimulated the theoretical research which led to Henk van de Hulst's prediction of the $21 \mathrm{~cm}$ hydrogen line. His 32 foot home-built radio telescope was the largest parabolic dish ever built at that time, and his development of focal plane feeds and receivers set the stage for later generations of radio telescopes and the ubiquitous home satellite receivers. ${ }^{71}$ His innovative receiver designs became known to British radar workers and were implemented in World War II radar systems. ${ }^{72}$

Reber also had another, perhaps less well recognized, impact on radio astronomy. Of the many astronomers who were first exposed to radio astronomy through early visits to Wheaton, three went on to play major roles in the future development of the field. Otto Struve would become the first director of NRAO; Bart Bok, perhaps influenced by his student, Jesse Greenstein, began the radio astronomy program at Harvard where many of the early NRAO staff got their start in radio astronomy; and Greenstein himself went on to start the radio astronomy group at Caltech. Both Greenstein and Bok were also to play major roles in the creation of NRAO (Chap. 3). Later, Reber's contacts with science policy leaders such as Lloyd Berkner, Vannevar Bush, and Merle Tuve may have helped to stimulate their interests in radio astronomy and their contributions to the establishment of and large investment in radio astronomy in Australia, at Caltech, and at NRAO. 
Although Karl Jansky was the first to detect cosmic radio emission, it was Grote Reber, who through his innovative experiments, forceful personality, and stubborn persistence finally convinced astronomers that radio astronomy might be important, thus opening a new window on the Universe. He worked alone in a previously unexplored part of the electromagnetic spectrum, designing and building his own equipment, and he was surely the only astronomer, perhaps the only scientist, in the modern era to accomplish so much while working alone as an amateur.

Over a period of less than a decade, working alone and only part time, Grote Reber established the nonthermal nature of the galactic radio emission, recognized that the radio sky was very different from the visual sky, based on his radio maps speculated on the spiral arm nature of the Galaxy, and published the first observations of radio emission from the Sun and later the remarkably intense solar radio emission associated with the active Sun. He showed, for the first time, that radio observations were more than a curiosity. He was the first to appreciate the potential of shorter wavelengths for radio astronomy and was the first to introduce the parabolic dish for radio astronomy. Throughout his life, he argued in support of long wavelength radio astronomy and the development of phased arrays over expensive steerable dishes. Microwave technology had not yet caught up with his ambitions. It would take the wartime development of microwave electronics to open up the microwave, then later millimeter-wave, bands for radio astronomy, and it would take the later development of high speed digital electronics before radio astronomers again seriously considered observing the meter and decameter wavelength sky.

Both Jansky and Reber made the profound observation that the radio sky is very different from the visual sky, foreshadowing the remarkable radio astronomy discoveries of the next half century. Ironically, after the end of World War II, it was in the UK and Australia that former radar scientists followed up on Jansky and Reber's observations of galactic and solar radio emission. In the US the few radio astronomy programs were largely driven by Cold War defense interests and, until the NSF initiative to develop a national radio astronomy facility, the embryo US radio astronomy programs were largely funded by the military - the Office of Naval Research (ONR) or the Air Force Office of Scientific Research (AFOSR).

\section{Notes}

1. This section is based in part on correspondence between Karl and his parents held at the University of Wisconsin Archives, from Jansky's notes and reports held in the Bell Labs Archives, from other Jansky family correspondence, and from discussions and correspondence with former Bell Labs Scientist, J.A. (Tony) Tyson, as well as with Karl's wife, children, and sister. We are grateful to David Jansky who has kindly made family correspondence and documents available to us. 
2. Jansky did not receive his Master's degree until 1936, after submitting a thesis based on his work at Bell Labs.

3. H. Friis confirmed the influence of C.M. Jansky, Jr. in hiring Karl at Bell Labs during his 1965 interview with R. Kestenbaum, NAA-KGJ, Bell Labs Oral Interviews, and also in a 22 November 1955 letter to J.R. Howland, NAA-KGJ.

4. KGJ to parents, 5 May 1933, NAA-KIK, Open Skies, Chap. 1. Karl and his wife Alice regularly corresponded with Karl's parents. As a Professor of Electrical Engineering at the University of Wisconsin, Karl's father was interested in Karl's work, which Karl carefully described in his letters. Although addressed to Karl's mother and father as well as his younger siblings still living at home, Karl's technical remarks were clearly directed to his father. When Karl's parents sold their home in Madison, the new owners found these letters in the attic, and, aware of their historical value, donated them to the University of Wisconsin Archives. We are indebted to the University Archivist, Bernard Schermetzler, for making these letters available.

5. Jansky's notebook and his work reports were located in the Bell Labs Archives by J.A. Tyson, who kindly made copies available to the authors. NAA-KIK, Open Skies, Chap. 1.

6. KGJ to parents, NAA-KIK, Open Skies, Chap. 1.

7. Edmond Bruce was a Member of the Bell Labs Technical Staff who had invented the antenna array which bears his name. There is some evidence that he had independently detected excess noise which appeared to be extraterrestrial, but he never followed this up.

8. The classical Bruce Array was bidirectional. By adding a parasitic reflector element, Jansky's array was omni-directional. The array had an azimuth beamwidth of 24 degrees and elevation beamwidth of 36 degrees (Sullivan 1978).

9. Jansky's notebook entry, pg. 81. Bell Laboratory Archives, Photocopy: NAAKIK, Open Skies, Chap. 1. Jansky later found interfering signals at 14.5 meters and changed his observing wavelength to 14.6 meters.

10. KGJ to his parents, 5 December 1930, NAA-KIK, Open Skies, Chap. 1.

11. KGJ to his parents, 27 November 1932, NAA-KIK, Open Skies, Chap. 1.

12. Karl's older brother Moreau later recalled that he was probably the chair of the session. R. Kestenbaum interview with C.M. Jansky, Jr., 11 May 1965, NAAKGJ, Bell Labs Oral Interviews. See also note 29.

13. KGJ to parents, 18 January 1933, NAA-KIK, Open Skies, Chap. 1.

14. KGJ to parents, 31 July 1932, NAA-KIK, Open Skies, Chap. 1.

15. KGJ to parents, 5 May 1933, NAA-KIK, Open Skies, Chap. 1. We are indebted to J. Goldbaum, NASEM Archivist, for providing us with a copy of the 27 April 1933 URSI agenda.

16. Russell Ohl, oral history conducted in 1965 by F. Polkinghorn, IEEE History Center, Hoboken, NJ; R. Ohl interview by L. Hoddeson, 20 August 1976, AIP.

17. Transcript of the 15 May 1933 NBC WJZ interview with Karl Jansky, NAAKIK, Open Skies, Chap. 1.

18. KGJ to parents, 10 May 1933, NAA-KIK, Open Skies, Chap. 1.

19. C.M. Jansky Jr. to C.M. Jansky, 16 May 1933; KGJ to parents, 25 May 1933, NAA-KIK, Open Skies, Chap. 1.

20. KGJ to his parents, 10 May 1933, NAA-KIK, Open Skies, Chap. 1. 
21. John Kraus (1984) later reported that less than two dozen people heard Jansky's historic talk.

22. KGJ to his parents, 22 January 1934, NAA-KIK, Open Skies, Chap. 1.

23. Copies of Sir Edward Appleton's 1948 URSI Presidential Address were found in the papers of C.M. Jansky, Jr., donated to the NRAO/AUI Archives by Karl's son David. NAA-KGJ, Correspondence, Family Correspondence.

24. The MUSA array near Manahawkin, New Jersey was used together with an identical array in the UK by President Roosevelt to communicate with British Prime Minister Winston Churchill during WWII.

25. R. Kestenbaum interview with A. Beck, 10 February 1965, NAA-KGJ, Bell Labs Oral Interviews.

26. GR to G. Southworth, 15 April 1960, NAA-GR, General Correspondence. https://science.nrao.edu/about/publications/open-skies\#section-1

27. J.C. Schelleng to G. Du Shane, 16 October 1956, and 8 November 1956, NAA-KIK, Open Skies, Chap. 1.

28. H. Friis to C.M. Jansky, Jr., 23 January 1958, NAA-KIK, Open Skies, Chap. 1.

29. In his 1965 interview with Ray Kestenbaum and in the referenced publications, Friis firmly and repeatedly held the position that Jansky never asked to continue his star noise work, but at the same time he noted that had Karl lived longer, he surely would have received the Nobel Prize for his discovery of galactic radio emission. NAA-KGJ, Bell Labs Oral Interviews.

30. C. M. Jansky, Jr. to Alice Jansky Knopp, 7 February 1958, NAA-KIK, Open Skies, Chap. 1 (Alice had remarried Otto Knopp).

31. Alice Jansky Knopp to C.M. Jansky, Jr., 11 February 1958, NAA-KIK, Open Skies, Chap. 1.

32. C.M. Jansky, Jr. to Alice Jansky Knopp, 26 March 1958, NAA-KIK, Open Skies, Chap. 1.

33. Audio recordings of these interviews were retained at the Bell Labs Archives. In 1997, J.A. Tyson kindly made copies available to NRAO. With Tyson's permission, the recordings have been transcribed and posted on the Web, See NAAKGJ, Bell Labs Oral Interviews.

34. G. Southworth to R. Kestenbaum, 10 March 1965, NAA-KIK, Open Skies, Chap. 1.

35. L. Espenschied to G. Southworth, 21 February 1965, NAA-KIK, Open Skies, Chap. 1.

36. G. Southworth to L. Espenschied, 23 February 1965, NAA-KIK, Open Skies, Chap. 1.

37. R. Ohl, 1976, op. cit.

38. C.M. Jansky, Jr. to Karl, Alice and Anne Moreau, 9 May 1933, NAA-WJS, Cosmic Noise, Working Papers, K.G. Jansky.

39. KGJ to parents, 10 June 1933, NAA-KIK, Open Skies, Chap. 1.

40. KGC to parents, 5 May 1933, NAA-KIK, Open Skies, Chap. 1.

41. KGJ to his parents, 22 January 1934, NAA-WJS, Cosmic Noise, Working Papers, K.G. Jansky.

42. G. Reber to J. Pfeiffer, 31 January 1955, NAA-GR, General Correspondence I.

43. R. Ohl, 1975 op. cit.

44. Cyril Jansky to Karl, Alice and Anne Moreau, 9 May 1933, NAA-WJS, Cosmic Noise, Working Papers, K.G. Jansky.

45. KGJ to his parents, 22 January 1934, op. cit. 
46. The first suggestions that the nonthermal cosmic radio emission was due to synchrotron radiation was by Alfvén and Herlofson (1950) and Kippenheuer (1950), but it was the quantitative papers by Ginzburg (1951) and Shklovsky (1952) that convinced the astronomical community of its relevance.

47. Alice Jansky Knopp to Sir Edward Appleton, 17 April 1950, NAA-KGJ, Correspondence, Family Correspondence. The letter indicates that Alice had previously written to Appleton while Karl was still alive to promote his case for the Nobel Prize.

48. Martin Ryle and Anthony Hewish in 1974, for aperture synthesis and pulsars respectively; Arno Penzias and Robert Wilson in 1978, for their discovery of the cosmic microwave background; Russell Hulse and Joseph Taylor in 1993, for their discovery of a new type of pulsar that opened up new possibilities for the study of gravitation; and John Mather and George Smoot in 2006, for their discovery of the blackbody form and anisotropy of the cosmic microwave background.

49. JLG to GR, 13 March 1962, NAA-GR, General Correspondence I. https:// science.nrao.edu/about/publications/open-skies\#section-1

50. Ibid.

51. Oral interviews WTS with Gennady Potapenko, 26 December 1974, 21 August 1975, NAA-WTS, Working Files, Interviewees, Potapenko. https://science. nrao.edu/about/publications/open-skies\#section-1

52. Additional material on DeWitt's measurements may be found in Sullivan's papers in the NRAO Archives, NAA-WTS, Working Papers, DeWitt.

53. This section on Grote Reber is adapted from Kellermann (2004), with permission from the Astronomical Society of the Pacific, and is based in part on Reber's (1958) paper describing his early experiments in Wheaton. In his paper, which was published in a special edition on radio astronomy in the Proc. IRE, Reber describes the details of his antenna, feeds, and the receivers that he constructed and used to study celestial radio emission during the period 1937-1947.

54. GR oral interview with KIK, 13 June 1994, NAA-KIK, Oral Interviews.

55. Alberta Adamson interview with GR at Wheaton History Center, 19 October 1985, transcribed at NRAO, NAA-GR, Oral History Interviews.

56. Ibid.

57. NAA-GR, Notes and Papers, 1938. https://science.nrao.edu/about/publications/open-skies\#section-1

58. GR to R. Langer, 7 July 1937, NAA-GR, General Correspondence. https:// science.nrao.edu/about/publications/open-skies\#section-1

59. GR to Edwin Hubble, 5 January 1939, NAA-GR, General Correspondence. https://science.nrao.edu/about/publications/open-skies\#section-1

60. GR to KGJ, 26 April 1937, NAA-GR, General Correspondence. https://science.nrao.edu/about/publications/open-skies\#section-1

61. The angular resolution depends on the size of the telescope aperture measured in wavelengths, so for a fixed antenna size the resolution is better at shorter wavelengths.

62. According the Rayleigh-Jeans radiation law the intensity of the thermal radiation from a hot body is inversely proportional to the square of the wavelength. So by going to the shortest wavelengths technically feasible, Reber hoped to achieve the best possible angular resolution and also anticipated that for any given temperature that the radio radiation would be about 25,000 times stron- 
ger than that detected by Jansky. Since the galactic radiation is weaker at the shorter wavelength, it is considered "non-thermal."

63. S. Reber to GR, 16 December 1938, NAA-GR, General Correspondence I. https://science.nrao.edu/about/publications/open-skies\#section-1

64. F. Whipple to GR, 22 December 1938, NAA-GR, General Correspondence I. https://science.nrao.edu/about/publications/open-skies\#section-1

65. JLG, I Was there in the Early Years of Radio Astronomy, unpublished and undated manuscript, NAA-KIK, Open Skies, Chap. 1.

66. GR oral interview with Alberta Adamson, Wheaton History Center, 19 October 1985, NAA-GR, Oral Interviews.

67. JLG unpublished manuscript, op. cit.

68. In 2019, it still takes 51 minutes.

69. KIK Oral interview with GR, 25 May 1991, NAA-KIK, Oral Interviews.

70. J. Pierce to J.A. Tyson, 23 April 1998, Dedication of the Jansky Monument (Holmdel: Bell Labs).

71. Development of the German Wurzburg-Riese 7.5 meter (25 feet) radar antennas used during WWII probably started before 1940, but of course this was not known to Reber.

72. Private communication, Sir Bernard Lovell to KIK, May 2007.

\section{BIBLIOGRAPHY}

\section{REFERENCES}

Alfvén, H. and Herlofson, N. 1950, Cosmic Radiation and Radio Stars, Phys. Rev., 78, 616

Beck, A. 1984, Personal Recollections of Karl Jansky. In Serendipitous Discoveries in Radio Astronomy, ed. K.I. Kellermann and B. Sheets (Green Bank: NRAO/AUI), 32 Bown, R. 1927, Transatlantic Radio Telephony, Bell Laboratory Technical Journal, 6, 248 Contopoulos, G. and Jappel, A. eds. 1974, Transactions of the IAU XV - B (Dordrecht: Reidel)

Edmondson, F. 1956, Review of The Changing Universe. The Story of the New Astronomy, Science, 124, 541

Ewen, H.I. and Purcell, E.M. 1951, Observation of a Line in the Galactic Spectrum, Nature, 168, 356

Franz, K. 1942, Messung der Empfangempfindlichkeit, Hochfrequenztechnik. und. Elektroakustik, 59, 143

Friis, H.T. 1965, Karl Jansky: His Career at Bell Telephone Laboratories, Science, 149, 841

Friis, H.T. 1971, Seventy-five Years in an Exciting World (San Francisco: San Francisco Press)

Friis, H.T. and Feldman, C.B. 1937, A Multiple Unit Steerable Antenna for Short-Wave Radio Reception, Bell Tech J., 16, 337

Ginzburg, V.I. 1951, Cosmic Rays as a Source of Galactic Radio Emission, Dokl. Akad. Nauk SSSR, 76, 377 (in Russian, English translation in W. Sullivan, Classics in Radio Astronomy (Dordrecht: Reidel), 93

Henyey, L.G. and Keenan, P.C. 1940, Interstellar Radiation from Free Electrons and Hydrogen Atoms, ApJ, 91, 625 
Hubble, E. 1929, A Relation between Distance and Radial Velocity among ExtraGalactic Nebulae, PNAS, 15, 168

Jansky, C.M. Jr. 1957, The Beginnings of Radio Astronomy, American Scientist, 45 (1), 5

Jansky, C.M. Jr. 1958, The Discovery and Identification by Karl Guthe Jansky of Electromagnetic Radiation of Extraterrestrial Origin in the Radio Spectrum, Proc. IRE, 46, 13

Jansky, K.G. 1932, Directional Studies of Atmospherics at High Frequencies, Proc. IRE, 20, 1920

Jansky, K.G. 1933a, Radio Waves from Outside the Solar System, Nature, 132, 66

Jansky, K.G. 1933b, Electrical Disturbances Apparently of Extraterrestrial Origin, Proc. IRE, 21, 1387

Jansky, K.G. 1933c, Electrical Phenomena that Apparently Are of Interstellar Origin, Popular Astronomy, 41, 548

Jansky, K.G. 1935, A Note on the Source of Interstellar Interference, Proc. IRE, 23, 1158 Jansky, K.G. 1937, Minimum Noise Levels Obtained on Short Wave Receiving Systems, Proc. IRE, 25, 1517

Jansky, K.G. 1939, An Experimental Investigation of the Characteristics of Certain Types of Noise, Proc. IRE, 27, 763

Kellermann, K.I. 2004, Grote Reber (1911-2002), PASP, 116, 703 (https://doi. org/10.1086/423436)

Kent, G. 1958, A New Window on the Sky, Readers Digest, 72, 91

Kippenheuer, K.O. 1950, Cosmic Rays as the Source of General Galactic Radio Emission, Phys. Rev., 79, 738

Kraus, J. 1981, The First 50 Years of Radio Astronomy, Part 1: Karl Jansky and His Discovery of Radio Waves from Our Galaxy, Cosmic Search, 3 (4), 8

Kraus, J. 1984, Karl Guthe Jansky's Serendipity, Its Impact on Astronomy and its Lessons for the Future. In Serendipitous Discoveries in Radio Astronomy, ed. K.I. Kellermann and B. Sheets (Green Bank: NRAO/AUI), 57

Langer, R.M. 1936, Radio Noise from the Galaxy, Phys. Rev., 49, 209

Levy, D.H. 1993, The Man Who Sold the Milky Way: a Biography of Bart Bok (Tucson: University of Arizona Press)

Lovell, A.C.B. 1984, Impact of World War II on Radio Astronomy. In Serendipitous Discoveries in Radio Astronomy, ed. K. Kellermann and B. Sheets (Green Bank: NRAO/AUI), 89

Oswald, A.A. 1930, Transoceanic Telephone Service-Short Wave Equipment, Trans. AIEE, 49, 629

Pfeiffer, J. 1956, The Changing Universe: The Story of the New Astronomy (New York: Random House)

Penzias, A. and Wilson, R.W. 1965, A Measurement of Excess Antenna Temperature at $4080 \mathrm{Mc} / \mathrm{s}$, ApJ, 142, 1149

Reber, G. 1940a, Cosmic Static, Proc. IRE, 28, 68

Reber, G. 1940b, Cosmic Static, ApJ, 91, 621

Reber, G. 1942, Cosmic Static, Proc. IRE, 30, 367

Reber, G. 1944, Cosmic Static, ApJ, 100, 279

Reber, G. 1948a, Cosmic Static, Proc. IRE, 36, 1215

Reber, G. 1948b, Cosmic Radio Noise, Radio-Electronic Engineering, July 1948

Reber, G. 1949a, Galactic Radio Waves, SéT, 8, 139

Reber, G. 1949b, Radio Astronomy, Scientific American, 181, 34

Reber, G. 1950, Galactic Radio Waves, ASP Leaflet No. 259 
Reber, G. 1958, Early Radio Astronomy in Wheaton, Illinois, Proc. IRE, 46, 15

Reber, G. 1982, A Timeless, Boundless, Equilibrium Universe, PASAu, 4, 482

Reber, G. 1988, A Play Entitled the Beginning of Radio Astronomy, JRASC, 82, 93

Reber, G. and Greenstein, J.L. 1947, Radio Frequency Investigations of Astronomical Interest, Observatory, 67, 15

Shklovsky, I.S. 1952, On the Nature of Radio Emission from the Galaxy, Astr. Zhur. SSSR, 29, 418

Southworth, G.C. 1956, Early History of Radio Astronomy, Scientific Monthly, $82(2), 55$

Sullivan, W.T. III 1978, A New Look at Karl Jansky's Original Data, SerT, 56, 101

Sullivan, W.T. III 2009, Cosmic Noise (Cambridge: CUP)

Whipple, F.L. and Greenstein, J.L. 1937, On the Origin of Interstellar Radio Disturbances, PNAS., 23, 177

Zwicky, F. 1969, Discovery, Invention, Research (New York: Macmillan)

\section{Further READING}

Jansky, C.M. Jr. 1979, My Brother Karl Jansky and his Discovery of Radio Waves from Beyond the Earth, Cosmic Search, 1 (4), 12

Jansky, D. 1984, My Father and His Work. In Serendipitous Discoveries in Radio Astronomy, ed. K. Kellermann and B. Sheets (Green Bank: NRAO/AUI), 4

Kellermann, K.I. 1999, Grote Reber's Observations on Cosmic Static, ApJ, 525, 37

Kellermann, K.I. 2003, Grote Reber (1911-2002), Nature, 421, 596

Kellermann, K.I. 2005, Grote Reber (1911-2002): A Radio Pioneer. In The New Astronomy: Opening the Electromagnetic Window and Expanding our View of Planet Earth, ed. W. Orchiston (Dordrecht: Springer), 43

Kraus, J. 1982, The First 50 Years of Radio Astronomy, Part 2: Grote Reber and the First Radio Maps of the Sky, Cosmic Search, 4 (1), 14

Kraus, J. 1988, Grote Reber, Founder of Radio Astronomy, JRASC, 82, 107

Parsons, A.M.J. 1984, Personal Recollections for the Green Bank Symposium. In Serendipitous Discoveries in Radio Astronomy, ed. K. Kellermann and B. Sheets (Green Bank: NRAO/AUI), 22

Reber, G. 1948, Solar Intensity at 480 Mc, Proc. IRE, 36, 88

Reber, G. 1955, Fine Structure of Solar Transients, Nature, 175, 78

Sullivan, W.T. III 1984a, Karl Jansky and the Beginnings of Radio Astronomy. In Serendipitous Discoveries in Radio Astronomy, ed. K. Kellermann and B. Sheets (Green Bank: NRAO/AUI), 39

Sullivan, W.T. III 1984b, The Early Years of Radio Astronomy (Cambridge: CUP) 
Open Access This chapter is licensed under the terms of the Creative Commons Attribution 4.0 International License (http://creativecommons.org/licenses/ by $/ 4.0 /)$, which permits use, sharing, adaptation, distribution and reproduction in any medium or format, as long as you give appropriate credit to the original author(s) and the source, provide a link to the Creative Commons licence and indicate if changes were made.

The images or other third party material in this chapter are included in the chapter's Creative Commons licence, unless indicated otherwise in a credit line to the material. If material is not included in the chapter's Creative Commons licence and your intended use is not permitted by statutory regulation or exceeds the permitted use, you will need to obtain permission directly from the copyright holder. 